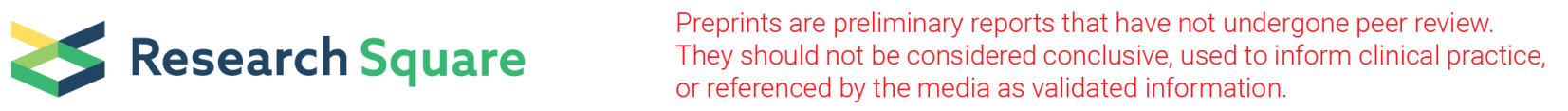

\title{
Social gradient in health-related quality of life among urban residents in Limassol, Cyprus: Research article
}

Panagiota Ellina ( $\sim$ giwta.ell@hotmail.com )

Cyprus University of Technology https://orcid.org/0000-0001-8611-8939

Nicos Middleton

Cyprus University of Technology Faculty of Health Sciences

Ekaterini Lambrinou

Cyprus University of Technology Faculty of Health Sciences

Christiana Kouta

Cyprus University of Technology Faculty of Health Sciences

Research article

Keywords: Social inequalities, Quality of health, SF 36, Social status, Gender

Posted Date: August 17th, 2020

DOI: https://doi.org/10.21203/rs.3.rs-18661/v3

License: () (1) This work is licensed under a Creative Commons Attribution 4.0 International License. Read Full License

Version of Record: A version of this preprint was published at BMC Public Health on March 29th, 2021. See the published version at https://doi.org/10.1186/s12889-020-10027-6. 


\section{Abstract}

Background: Social inequalities in health threaten social cohesion and, therefore, their investigation is an important research field. Monitoring the health of the population is necessary to identify health needs, design programs focused in people's needs and to evaluate the effectiveness of health policies.

Methods: A cross-sectional survey using primary data was applied. The study investigates the size and the extent of social inequalities in quality of life and health behaviours in Limassol, Cyprus. Data collection was done by door-to-door survey, in the form of interviews. The sample consisted of 450 residents aged 45-64 across 45 randomly selected neighbourhoods, that met the selection criteria. The tools used were: Demographic questionnaire, SF 36 Questionnaire, IPAQ- International Physical Activity Questionnaire short form.

Results: The social gradient appears in all social indicators. As for the physical dimension of health has a strong relationship between health-related quality of life with the education index. Specifically, the difference between the two poles is 12 points for men and 14 points for women ( $p=0.16)$. Profession systematically appears to have a stronger relationship with men than with women, and is present in both physical and mental dimensions. Specifically, the difference between the two poles is 13 points for men and 10 points for women $(p=0.31)$.

Conclusions: Exploring social inequalities in health-related quality of life, is a complex situation influencing social, physical and psychological health state. It seems that young male individuals, who are highly educated, employed full time, earning high incomes and engaging in mild physical activity, have significantly higher level of health-related life quality, compared to other middle age adult groups, living in Limassol. This finding is in agreement with other studies that show correlations between gender and the patterns of risk factors.

\section{Background}

Social inequalities in health refer to systematic differences in health between different socio-economic groups. When three characteristics are presented in combination, it is the noticeable difference between what one would perceive as a simple fluctuation in health and social inequality in health. When the observed differences are systematic, they are considered as the effect of unbalanced social processes (which are modifiable) and an indication of unfairness [1].

Social inequalities in health threaten social cohesion. Poverty reduction, provision of effective health care to citizens and improvement of the quality of life, are long-term goals ensuring social and economic cohesion $[2,3,4]$.

Social inequalities in health have been widely investigated. Researchers on health inequalities in recent decades have devoted considerable effort to identifying specific social, environmental or behavioral factors (eg occupational status, physical activity) that explain the relationship between social status and health $[5,6,7]$. The environment where one lives, plays a crucial role in this matter. However, the existence of socio-economic disadvantage, psychosocial effects (social cohesion), health behaviors, gender can partially explain the social classification of health [4, 6, 7-9]. 3, 5, 6- 8].

It is generally accepted that no single factor can explain these inequalities in health, due to the combined and accumulative effect of risk factors over time and in different life domains [10]. It also seems that men and women are exposed differently in these determinants or that they are otherwise vulnerable to these determinants [11-13]. Women have lower mortality rates but, paradoxically, report higher levels of depression, psychiatric disorders and various chronic diseases than men $[10,12,13] .9,11,12]$.

Usually, there is a gradual, if not even linear, decreasing trend in the health status the lower the social status of the individual - this is not simply the case where poor health is confined to a single social group at the extreme end of the scale, while all other groups have relatively good health levels - this is referred to as social gradient [14].

Sometimes, the impact of the social gradient in health is expressed as shortfall - which basically is expressed as the number of lives that would not have been lost if all groups in society enjoyed the same standard of life, as those in the most advantageous position [14]. For example, the shortfall in life expectancy for women in the lowest income group was around 26.7 years, compared to women - belonging to the highest income group [15].

In addition, there is increasing interest in monitoring the quality of life through perceived health status (self-assessment of health). This measure has been shown through longitudinal studies to be related to the provision for subsequent hospitalization or mortality [16-19].

Monitoring the health of the population is vital for several reasons. The resulting information is laid necessary to identify health needs, design programs and to evaluate the effectiveness of health policies [16].

\section{Impact in community nursing and public health}

The existence of social inequalities in health is a challenge for public health. At the same time, public health is a core of work for all nurses. Nurses face the daily effects of social inequalities on the health and well-being of the communities they care for, such as inadequate access to health care services and increased morbidity and mortality rates. Because nurses experience the impact of social determinants on health, both the patients they provide care to and the general population, have a clear stake in identifying and addressing the causes of "poor" health. Empowering people to get control of their lives, will help considerably to take control of their health and, having nursing presence beside them [20].

The results of this study can be utilized by community nurses by applying approaches aimed at reducing health inequalities, ensuring health and well-being, ensuring the effectiveness of initiatives and providing assistance to health providers and local authorities, in order to fulfill their obligations. 
Community actors and local authorities should take into account the results of the research in order to take action in areas with the lowest values in people's quality of life by implementing programs aimed at ensuring the well-being of citizens.

\section{Methods}

\section{Aim}

The purpose of this paper was to investigate the size and the extent of social inequalities in quality of life and health behaviours in Limassol.

\section{Design}

This is a cross-sectional survey using primary data.

\section{Study participants}

\section{Sampling method}

Multistage sampling was performed in four stages - parishes and communities, neighbourhoods (specific streets as a starting point from all parishes), homes (households), and finally, people.

- For municipalities and communities, a stratified random sampling was used in terms of urban areas, community size and generally accepted socioeconomic indicators, to ensure that municipalities/communities from the entire range of socioeconomic classification were selected. Specifically, parishes and communities were ranked in terms of the percentage of the population with university education, an indicator which is one of the most commonly accepted socio-economic indicators and was the only one available at the stage of sampling from the open access files of the Statistical Service of Cyprus.

- Neighborhoods: In order to select neighborhoods from the whole range of socio-economic scale as well as to achieve wider geographical coverage, it was decided to include streets from all the parishes of the city of Limassol.

- Households: The households that participated in the study were selected in a systematic way. In the city, the field researcher started from one end of the road and moved along its entire length, selecting every third-fourth house, on the left and right side of the road alternately. Where it was not possible to recruit 10 people by the end of the selected street (e.g. refusal to participate, no one is home, etc.), the researcher completed the sample with households from the wider neighborhood - which is defined in the case of study as all lanes beginning / ending or crossing the selected street until the next intersection. In the case of an apartment building, a similar practice of systematic sampling based on the floors and the apartments was applied, e.g. left apartment on the 1st floor, right apartment on the 3rd floor accordingly avoiding repeating the same pattern always.

- People: quota sampling was used at household level (50:50, male female alternately in each household). The medical history of each person who participated in the research was not asked, as long as the person could answer the questions in the questionnaire. When the researcher had the required numbered, she stopped, but she was trying to get people from the beginning, middle and end of the road.

Sample size

The population of the city of Limassol was divided into quarters, depending on its socio-economic status and specifically on the percentage of the population with university education.

The estimation of sample was based on power analysis. The result size in this population group in the city of Limassol is $f=0.20-0.25$ (the which corresponds to a moderate effect size). The sample size of 188-300 individuals provides $90 \%$ statistical power to detect a difference in statistical significance level of $5 \%$. The minimum desired sample in urban areas was set at 450 people. The sample size ensures a similar level of statistical power to detect such a degree social gradient in the quality of life in both genders separately, at least in urban areas (225 men and 225 women). Finally, it should be noted that, due to the nature of the study, which is based on multi-stage random sampling of neighbourhoods/communities and households, it was taken into account that the sample size should also ensure the greatest possible geographical coverage and include neighbourhoods with diverse socioeconomic background. Therefore, in terms of the objectives of the study, it is preferable in such cases that the sample consists of as many neighbourhoods/communities as possible rather than selecting many people from a small number of neighbourhoods and communities, so that the sample is more representative of the whole range of socio-economic disadvantage, which is expected to be concentrated in the area. The minimum number of people per neighbourhood / area was set at 10 people.

Also, it should be mentioned that the specific sample size is considered satisfactory as it provides statistical accuracy of \pm 5 percentage points for the $95 \%$ confidence interval in the estimation of percentages (eg smoking).

In order to ensure a satisfactory response rate, postal communication (distribution of an open letter to all homes on the preselected roads) informed prospective participants that a university researcher would visit them for a short interview in the next few days. Information was also given on the importance and contribution of the study with the request to participate.

\section{Inclusion criteria}

- People aged 45 to 65 , to include middle age adults as the economically active population who has completed their studies, has a family, has income, and therefore has been integrated into their own professional, income and social status. The choice of the $45-65$ age group was based on two popular 
hypotheses, which seek to explain the mechanisms that lead to the effect of socio-economic status on health in old age. These hypotheses are: the "cumulative disadvantages / advantages" hypothesis and the "age as a leveler" hypothesis (Kingston et al., 2015). Health inequalities appear to be smaller at younger ages, wider at middle and early older ages, and smaller again at later ages (House, Lantz \& Herd, 2005; Dannefer, 2003).

- People who can speak and read in Greek

- Permanent residents in Limassol (or permanent resident or residence in Limassol for 5 years)

\section{Tools}

Demographic / socio-economic characteristics and lifestyle characteristics

Variables related to personal characteristics, such as demographic characteristics (age, gender, marital status, area where they reside), socio-economic characteristics (level of education, annual income, occupation), as well as lifestyle characteristics (smoking, alcohol, physical activity).

\section{Self-rated health}

The level of self-assessment of the individual's health was measured on a 5-point scale (Likert scale), ranging from excellent health to poor. Individuals were asked to evaluate their health as: $1=$ excellent, $2=$ very good, $3=$ good, $4=$ moderate and $5=$ poor.

\section{SF 36 Questionnaire - Quality of Life}

Quality of life questionnaire SF-36v2 Standard, Greek Version was used to measure quality of life of research participants. The questionnaire was created in 1992 [21], and is used in several countries for the self-esteem of the Quality of Life and comparing the health status of different population groups.

The SF-36 scale is a tool used to measure the health level of a population. Its basic attribute is the simultaneous measurement and assessment of the level of physical and mental health. The grid of 36 questions includes eight measurement scales consisting of questions that represent the most measured health dimensions. These scales are: physical functioning (PF), role physical (RP), bodily pain (BP), general health (GH), vitality (VT), social functioning (SF), role emotional (RE), and mental health (MH). The first four (4) dimensions make up the physical health, while other mental health of the individual. These eight scales are evaluated with a score ranging from 0-100 each, where 0 represents the minimum possible value and at the same time the worst health, while the maximum score of the scale, the value 100 is excellent health. Where a score of less than 50 this means that the person's health is below the average [22]. The generality of the SF-36 questions allows the adaptability of the questionnaire to each group of the population, while the Greek translation, as well as the entire questionnaire have been tested in repeated surveys in the health sector in Greece [23, 24] and Cyprus [25, 26].

\section{IPAQ- International Physical Activity Questionnaire short form}

The International Physical Activity Questionnaire short form (IPAQ) is a popular and frequently used questionnaire, which was developed in the late ' 90 s by a multinational working group, supported by the World Health Organization, to be used for comparative evaluation of physical population activity different groups and nationalities [27]. The IPAQ-short is also used by the European Union (Eurobarometer), while it has been tested in many international studies and is characterized by high reliability and satisfactory validity [27].

\section{Social status and indicators of socio-economic disadvantage}

The social status of the individual will be measured by the level of education, occupation, income.

Educational measurement refers to the highest level of education an individual attended (None / Primary, Secondary-Lower, Secondary-Upper, Undergraduate, Postgraduate studies).

Regarding the occupation, because the Cyprus Statistical Service classifies occupations only in the field of employment- which does not concern graduation, the Standard Occupational Classification of United Kingdom was used. Each participant was categorized according to his / her occupation.

The income indicator refers to the classification of individuals in relation to the monthly family income and was assessed according to the Cyprus Statistical Office standard through categories in which each participant was asked to choose one.

\section{Data collection procedure}

For the data collection the door-to-door survey method was employed. The survey was oral, in the form of an interview. The interviewer asked all participants the same set of questions and completed all sections of the questionnaire on paper during the interview. The interviewer visited each address once. 450 residents aged 45-64 (50:50 gender quota) across 45 randomly selected neighbourhoods (10 systematic random sample per area) from different city quarters, stratified by population density and proportion of adult residents with tertiary education.

The data was collected wherever the participant wanted, whether it was inside the house or at the door. The questionnaire filling time was about 10 minutes.

The data collection was mainly done in the afternoons, as during these hours were more likely to be at home the target group. In case of refusal to participate, the frequency (number of people who said they did not want to participate) was counted, to have an overview of the response rate (losses).

\section{Ethical considerations}


An opinion was sought from the Cyprus National Bioethics Committee and a reply has been received that this investigation does not fall within the remit of the CNBC for further bioethical evaluation. The participants, who wished to participate in the research, gave oral consent. In addition, anonymity and confidentiality of information were ensured, as only the researcher, research assistants and supervising professors had access. The questionnaires were destroyed after analyzing the data.

\section{Statistical Analysis}

Statistical analysis was performed using the statistical package IBM SPSS Statistics 23 and the significance level was set at $p<0,05$.

The mean value (M) and standard deviation (SD) were used to describe quantitative variables. Data concerning the International Physical Activity Questionnaire short form (I-PAQ) was entered in the IBM SPSS Statistics 23 Statistical Package according to the questionnaire's guide [28]. The import of SF36 questionnaire data was done using the special software Quality Metric Health Outcomes Scoring Software 5.0, which was provided free of charge by OPTUM. ANOVA was used statistical analysis in order to see the difference in both the physical dimension and the mental dimension of the tool, for the social status indicators (education, income and occupation). Linear regression was also used to calculate the correlation coefficient of movement at the different levels of the variables in relation to the quality of life (2 dimensions). The regression analysis was repeated as above, including the gender and the gender interaction with the social status indicator (education, income, occupation), in order to investigate the differential correlation of each variable with the quality of life as gender.

For the variable smoking, 3 categories were initially created (smokers, ex-smokers and non-smokers). Then, for a better evaluation of the smoking habit, the variable Pack-years of smoking was created, which was calculated with the following equation: pack-year of smoking = Years that someone smokes or smoked $\times$ (number of cigarettes per day) / 20. For the rest (non-smokers) the value is 0 .

\section{Results}

The survey response rate was $85.9 \%$, which is very high due to a previous postal communication (distribution of an open letter to all homes on the default streets) informing potential participants that a researcher from the university will follow up for a short interview in the next few days, as well as the importance and contribution of the study, with a request to participate.

\section{Demographics}

The participants were $50 \%(\mathrm{~N}=225)$ and $50 \%$ women $(\mathrm{N}=225)$. The majority were 93.3\% ( $\mathrm{N}=420)$ of Cypriot nationality, while the mean age of the sample was $53.7 \pm 6.54$. The results showed that $84 \%(\mathrm{~N}=378)$ of the sample were either married or cohabiting, while2.7\% ( $\mathrm{N}=12)$ stated to be single.

\section{Social status}

The majority of the participants $80.8 \%(\mathrm{~N}=364)$ has secondary upper and tertiary education Furthermore, 73.3\% $(\mathrm{N}=330)$ of the participants are employed either under full-time (68.4\%) or part-time (4.9\%). The family's monthly income seems to vary, $7.3 \%$ have a family monthly income of over $€ 5000$, while, 26.4\%, has between 1500 and 2000 euros.

\section{Health behaviours}

Participants were asked regarding smoking, alcohol and physical activity. More than half of the participants 57.8\% ( $\mathrm{n}=260$ ) reported to be non-smokers, while 35.8\% $(n=161)$ consisting of smokers. it appears that the participants consume alcohol in their socialization, since almost half of them $(41.6 \%, \mathrm{n}=187)$ reported consuming alcohol monthly. In relation to physical activity, $48 \%$ ( $\mathrm{n}=216)$ is classified as having mild physical activity, while only $15.8 \%(\mathrm{n}=71)$ is classified having intense physical activity. When participants were asked to evaluate their health (self-rated health), 39.3\% (n=177) reported excellent or very good, 44\% (n=198) good and 16.7\% ( $=75)$ moderate or poor.

\section{Quality of life}

Females seem to have lower scores in both dimensions of the SF-36. Especially in mental dimension, differences between the gender seems to be greater, because men have higher average values for all variables of mental dimension (Figure 1). Scores ranged from 4553.

Model of social status using individual characteristics and gender interaction 
The mean values for quality of life in physical and mental dimension were 49.7 (S.D=7.7) and 51.3 (S.D= 7) for men. The corresponding values for female gender are $50(S . D=8.5)$ and $48.8(S . D=7.9)$. Female gender seems to get lower in both dimensions of the SF-36. Especially in mental dimension, differences between the sexes seems to be stronger, because men have higher average values for all variables of the mental dimension.

The social gradient seems to be appeared in all social indicators (Table 1). As for the physical dimension of health, it seems that a strong relationship exists between quality of life with the

The pattern of social gradient exists when income is concerned. The physical component of the model shows a strong relationship between health-related quality of life and income, both in men and women ( $p<0.001)$. For women, the difference between the two poles is almost 11.5 points, while for men almost 10. The per category increase is 2.2 points for women and 1.8 for men. No differentiation is observed between gender $(\mathrm{p}$ for interaction $=0.9)($ Table 1$)$.

Regarding the classification of occupation, this seems to vary, since the relationship of the occupational status, irrespective of the way of classification, occupation seems systematically to present stronger relationship in men than in women, both in physical and mental dimensions. Specifically, the difference between the poles in the physical dimension of the tool is 13 in men and 10 in women. (Table 1 and Table 2).

\section{Model of social status using characteristics of the community/household (indicators of socio-economic disadvantage) and gender interaction}

The socio-economic disadvantage indicators were grouped into two categories. The first category named Educational and socioeconomic disadvantage includes the variables: Education, Non-Cypriot nationals, Non-Cypriot non-European citizens, Single parent households, Middle age, Households over 5, Unemployment, Not owner occupied and elementary agriculture occupations. The second category Structural disadvantage includes the variables: Housing units pre 1980, Housing units post 2001, Vacant temp houses, Apartment blocks and Apartment mixed use.

Physical dimension

The variable of education seems to be clearly presented the social gradient. The increase per category, in the whole sample, is 1.23 points and is statistically significant $(\mathrm{p}<0.001)$. The relationship between men and women differs. Specifically, in males the difference between the extremities (1st quadrant and 4th quadrant) is about 2 points, whereas in women this difference is around 6 points, and although it is not statistically significant $(\mathrm{P}=0.15)$, it is clinically significant on the scale of SF36. The other variables also present the social gradient, with no gender differences.

The variable apartment blocks presents the social gradient, but reverse. According to this variable, people who live in neighbourhoods with more apartment blocks (4th quarter) have better quality of life. The increase per category across the sample is 0.87 and the pattern does not differ between men and women.

\section{Mental dimension}

Regarding the mental dimension of the tool, it does not seem to be any gender differentiation (Table 2).

\section{Social Class and health behaviors}

Income

Smoking seems not to be related to the social status of a person (Table 3). Those with the highest smoking status> 50 pack years of smoking (15.2\%) do not appear to differ significantly from those to the lowest social position (20.6\%).

Regarding the frequency of alcohol consumption, it seems that people with higher income (higher social status) consume alcohol often or even daily $(6.1 \%)$, compared to people with lower social status who consume alcohol at the same frequency $(1.6 \%)(\mathrm{p}=0.002)$.

Physical activity did not appear to be related to income $(\mathrm{p}=0.07)$. 


\section{Education}

Education was statistically significant across all health behaviors under study. Compared to those with postgraduate education level who smoke> 50 pack years of smoking $(7.4 \%)$, those with none/primary education $(30.8 \%)$ are significantly much more $(p=0.006)$ (Table 3).

The same picture is seen in the frequency of alcohol consumption, where people with none/primary education (7.7\%) are much more, than people with postgraduate education $(0 \%)(\mathrm{p}<0.001)$.

Physical activity was statistically significantly correlated with education level $(\mathrm{p}=0.001)$. People with secondary-upper education level appear to have more physical activity (21.1\%), than those with none/primary education $(7.7 \%)$.

Classification of occupation

The occupation classification statistically significantly associated only with smoking $(\mathrm{p}=0.02)($ Table 4).

\section{Discussion}

\section{Main Results}

Compared to other studies [12, 29-32], that determine the social status of the individual with individual characteristics, our study investigated the quality of life, both in terms of individual characteristics and characteristics of the community/household (indicators of socio-economic disadvantage).

Social status using individual's characteristics and health-related quality of life

As in other studies, this study appears to have a strong correlation between demographic characteristics and health-related quality of life [16, 32-37]. In particular, a strong correlation appears to be associated with variables age (younger), level of education (older), income (older) and employment status (fulltime). The phenomenon of the healthy worker would explain to some extent the correlation observed in the quality of life. The healthy worker effect refers to the consistent tendency of active workers have a more favorable mortality experience than what the general population [38]. According to this phenomenon, workers usually have lower overall death rates than the general population, because seriously ill and chronic disabilities are usually excluded [39], from employment.

The results of the study show that women have lower values in all health-related quality of life indicators. These results are consistent with other studies in the literature showing that men receive higher average health-related quality of life than women $[16,33,41,42]$. Women are likely to experience multiple roles, many at the same time. The expectations others have of women in any of the multiple roles, may differ from the expectations of themselves and come into conflict with their goals as individuals [43].

Social status using characteristics of the community/household (indicators of socio-economic disadvantage) and quality of life

Indicators with the most statistical significance that reflect social gradient is the education level $(p=<0.001)$, unemployment $(p=0.001)$ and the absence of a computer $(p=0.001)$. Specifically, people who live in neighbourhoods where the education level is higher, unemployment is lower and most homes have a computer, have higher levels of quality of life. The above findings are consistent with studies investigating the health-related quality of life in relation to the socio-economic level [35].

Interaction of social status and gender

The exploration of social status (individual indicators) in relation to health-related quality of life was conducted using the variables of education level, income and classification of occupation. In contrast to other studies [12, 29-31], which do not show the social inclination and how this inclination differs between men and women, the phenomenon of social gradient is clear to the whole population, both for the physical dimension of the tool and for the mental.

In an attempt to explore whether the pattern is changing by studying both genders separately, it has been found that the pattern of social gradient remains, with women having a stronger relationship with the variable level of education and income, whereas this relationship appears to be reversed in the variable occupation, where men present the strongest relationship.

\section{Social status and health behaviors}

To some extent, health-related quality of life seems to be related to health behaviors, but health behaviors cannot fully explain this association. Health behaviors are not related to the observed gradation in the health-related quality of life of individuals.

\section{Comparison with other countries}

Compared to other selected studies in the literature, overall health-related quality of life indicators appear to be lower in Limassol. This is the case for both the physical dimension indicators and the mental dimension indicators. Athens is the only exception. Looking at the populations of Limassol and Athens individually, they appear to have a very similar picture in the 8 indicators of the tool (Figure 3). Scores ranged from 55-95. 


\section{Strengths of the analysis}

This study is ground-breaking for Cypriot standards since is the first time, that data from 45 neighbourhoods (streets) of Limassol are presented, regarding the size and the extent of social inequalities in health-related quality of life and health behaviors.

The results of the study can be used to inform and guide prevention strategies and programs aimed at reducing health inequalities.

This study explores the impact of social inequalities in health in a single city, but it is the starting point for raising awareness among other researchers about future studies with new research questions on health-related quality of life. In addition, it is the trigger for the study of other cities, beyond the city of Limassol.

In addition, this survey will raise the awareness of health professionals, especially those working in the community, about the impact of social inequalities on health-related quality of life.

\section{Limitations}

This study has been conducted only in the city of Limassol. However, it is the first study to give population norms for Cyprus. Unlike other countries, in Cyprus there is no ranking of the professions. For this purpose, the authors adopted the Standard Occupational Classification of United Kingdom.

In this study, the standard values of the general population of the United States of America were used, considering gender, as there are no standard rates for the general population of Cyprus.

From our decision to interview only during the afternoon hours, there was a bias, all those who did not meet the criteria were excluded.

The results were not adjusted for age because this survey has a specific age group as target (45-65 years old).

\section{Conclusions}

Exploring social inequalities in quality of life, is a complex state influencing social physical and psychological state of health. According to Wanderley [44], there is not a single study or a single tool capable of simultaneously clarifying the mechanisms identified as related to health and functionality (eg living conditions, financial status, marital status, lifestyle).

It seems that being male, young, highly educated, with high income, working full time and having a mild physical activity, results in a significant higher level of quality life in relation to others.

With respect to the characteristics of the community/household associated with social status, the results show that low levels of education, unemployment and the absence of a computer at home are significantly associated with low levels of quality of life. However, there is no indication to support any differentiation between men and women. Regarding linear regression with respect to individual's characteristics, the study showed that strong predictors associated with low health-related quality of life are all three individual characteristics of social status- education level, income, and occupation. This relationship seems to be stronger in women.

Many studies show that gender affects the patterns of risk factors and that this has a different impact on quality of life. Therefore, gender specificities must be taken into account in health prevention strategies [12, 32].

\section{Abbreviations}

HRQol: Health-related quality of life

\section{Declarations}

\section{Ethics approval and consent to participate}

Ethics approval for this study was received from the Cyprus National Bioethics Committee. Informed consent was taken from each participant and confidentiality was maintained by excluding the name of participants from the questionnaire and keeping the privacy during the interview time.

\section{Consent for publication}

Not Applicable.

\section{Availability of data and materials}

Authors' contributions

\section{Competing interests}

The authors declare that they have no competing interests. All authors read and approved the final manuscript. 


\section{Funding}

Not applicable.

\section{Competing interests}

The authors declare that they have no competing interests.

\section{References}

1. WHO: Constitution of the World Health Organization. who.int/governance/eb/who_constitution_en.pdf (2006). Accessed 10 Apr 2015.

2. OECD: Moving Beyond the Jobs Crisis - Supporting Material for Chapter 1 of the 2010 OECD Employment Outlook. oecd.org/employment/outlook (2010). Accessed 10 Apr 2015.

3. Juhasz A, Nagy C, Paldy A, Beale L. Development of a Deprivation Index and its relation to premature mortality due to diseases of the circulatory system in Hungary, 1998-2004. Social Science \& 2010; doi:10.1016/j.socscimed.2010.01.024.

4. Havard S, Deguen S, Bodin J, Louis K, Laurent O, Bard D. A small-area index of socioeconomic deprivation to capture health inequalities in France. Social Science \& Medicine. 2008; doi:10.1016/j.socscimed.2008.09.031.

5. Hemström Ö. Health inequalities by wage income in Sweden: the role of work environment. Sci. Med. 2005; doi:10.1016/j.socscimed.2004.12.028.

6. Hiyoshi A, Fukuda Y, Shipley MJ, Brunner EJ. Health inequalities in Japan: the role of material, psychosocial, social relational and behavioural factors. Sci. Med. 2014; doi: 10.1016/j.socscimed.2013.12.028.

7. Lahelma E, Pietiläinen O, Rahkonen O, Kivimäki M, Martikainen P, Ferrie J, et al. Social class inequalities in health among occupational cohorts from Finland, Britain and Japan: A follow up study. Health \& Place. 2015; doi:10.1016/j.healthplace.2014.12.004.

8. WHO: Impact of economic crises on mental health. euro.who.int/_data/assets/pdf_file/0008/134999/e94837.pdf (2011). Accessed 10 Apr 2015.

9. Hämmig O, Bauer GF. The social gradient in work and health: a cross-sectional study exploring the relationship between working conditions and health inequalities. BMC Public Health. 2013; doi: https://doi.org/10.1186/1471-2458-13-1170.

10. Hämmig O, Gutzwiller F, Kawachi I.The contribution of life style and work factors to social inequalities in self-rated health among the employed population in Switzerland. Social Science \& Medicine. 2014; doi: 10.1016/j.socscimed.2014.09.041.

11. Bor A, Matuz M, Gyimesi N, Biczók Z, Soós G, Doró P. Gender inequalities in the treatment of osteoporosis, Maturitas, 2015;80:162-169.

12. Prata J, Martins AQ, Ramos S, Rocha-Goncalves F, Coelho R. Gender differences in quality of life perception and cardiovascular risk in a community sample. Rev Port Cardiol. 2016; doi:10.1016/j.repc.2015.09.022.

13. Palencia L, Malmusi D, De Moortel D, Artazcoz L, Backhans M, Vanroelen C, Borrell C. The influence of gender equality policies on gender inequalities in health in Europe. Social Science \& Medicine. 2014; https://doi:10.1016/j.socscimed.2014.07.018.

14. WHO: Constitution of the World Health Organization. who.int/governance/eb/who_constitution_en.pdf (2006). Accessed 10 Apr 2015.

15. Hosseinpoor RA, Harper S, Lee HJ, Lynch J, Mathers C, Abou-Zahr C. International shortfall inequality in life expectancy in women and in men, 19502010. http://www.who.int/bulletin/volumes/90/8/11-097378/en/ (2012). Accessed: 20 of February 2015].

16. Audureau E, Rican S, Coste J. Worsening trends and increasing disparities in health-related quality of life: evidence from two French population-based cross-sectional surveys, 1995-2003. Qual Life Res. 2013; doi:10.1007/s11136-012-0117-7.

17. Kroenke CH, Kubzansky LD, Adler N, Kawachi I. Prospective change in health-related quality of life and subsequent mortality among middle-aged and older women. American Journal of Public Health. 2008; doi: 2105/AJPH.2007.114041.

18. Kaplan MS, Berthelot JM, Feeny D, McFarland BH, Khan S, Orpana H. The predictive validity of health-related quality of life measures: Mortality in a longitudinal population-based study. Quality of Life Research. 2007; doi: 1007/s11136-007-9256-7.

19. Gold M, Franks P, Erickson P. Assessing the health of the nation. The predictive validity of a preference-based measure and self-rated health. Medical Care. 1996;34(2): 163-177.

20. Royal College of Nursing: Health inequalities and the social determinants of health. http://www.rcn.org.uk/_data/assets/pdf_file/0007/438838/01.12_ Health_inequalities_and_the_social_determinants_of_health.pdf (2012). Accessed 16 Mar 2015.

21. Ware JE, Sheibourne CD. The MOS 36 item short form health survey (SF-36): I. conceptual framework and item selection. Med Care. 1992;30(6):473-83.

22. Saris-Baglama RN, Dewey CJ, Chisholm GB, Plumb E, King J, Kosinski M, et al. QualityMetric Health Outcomes Scoring Software 4 Lincoln, RI: QualityMetric Incorporated. 2010. https://www.amihealthy.com/download/InstallationGuide_ScoringSoftwareV4.pdf. Accessed 20 Nov 2019.

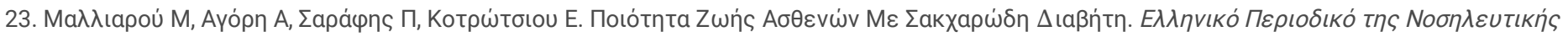

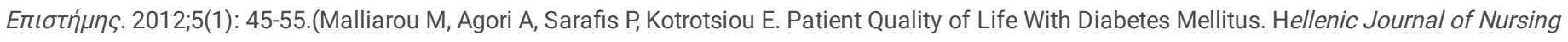
Science. 2012;5(1): 45-55.)

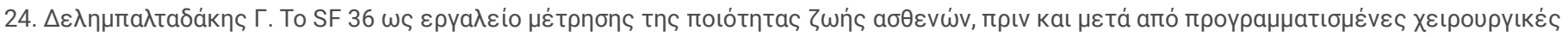
$\varepsilon \pi \varepsilon \mu \beta a ́ \sigma \varepsilon ı \varsigma . ~ \Delta ı a \theta \varepsilon \dot{\sigma \iota \mu o: ~ h t t p s: / / a p o t h e s i s . e a p . g r / h a n d l e / r e p o / 17887 ~(2008) . ~ П р o ́ \sigma ß a \sigma \eta: ~} 31$ Maptíou 2015.(Delimpaltadakis G. SF 36 as a tool for measuring patients' quality of life, before and after scheduled surgeries. https://apothesis.eap.gr/handle/repo/17887 (2008). Accessed 31 March2015.

25. Nicolaou C, Papathanassoglou E, Kouta C, Middleton N. Health-related quality of life, social support and social capital of mothers of children with cancer. European Journal of Public Health. 2015;25(30). doi: 1093/eurpub/ckv170.071.

Page 9/14 


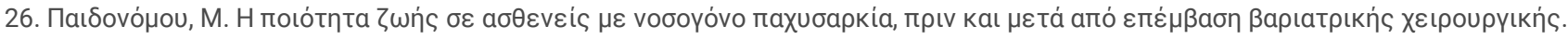
http://kypseli.ouc.ac.cy/handle/11128/1752 (2014). Прóбßaøn: 31 Mapriou 2015.(Paidonomou M. Quality of life in patients with morbid obesity, before and after bariatric surgery. http://kypseli.ouc.ac.cy/handle/11128/1752 (2014). Accessed 31 March 2015.

27. Craig CL, Marshall AL, Sjöström M, Bauman AE, Booth ML, Ainsworth, BE, et al. International physical activity questionnaire: 12 -country reliability and validity. Med Sci Sports Exerc. 2003;35(8):1381-95.

28. Guidelines for Data Processing and Analysis of the International Physical Activity Questionnaire IPAQ Short and Long Forms: Data Processing and Analysis of the International Physical Activity Questionnaire (IPAQ) - Short and Long Forms.

file:///C:/Users/George/Desktop/GuidelinesforDataProcessingandAnalysisofthelnternationalPhysicalActivityQuestionnairelPAQShortandLongForms.pdf (2005). Accessed 20 Nov 2017.

29. Garratt AM, Stavem K. Measurement properties and normative data for the Norwegian SF-36: results from a general population survey. Health and Quality of Life Outcomes. 2017; doi: 10.1186/s12955-017-0625-9.

30. Pietiläinen O, Laaksonen M, Pitkäniemi J, Rahkonen O, Lahelma E. Changes of occupational class differences in physical functioning: a panel study among employees (2000-2007). J Epidemiol Community Health. 2012; doi:10.1136/jech.2010.110270.

31. González-Rubio E, San Mauro I, López-Ruíz C, Díaz-Prieto1 L, Marcos A, Nova E. Relationship of moderate alcohol intake and type of beverage with health behaviors and quality of life in elderly subjects. Qual Life Res. 2016;25:1931-1942. Available from: doi: 10.1007/s11136-016-1229-2.

32. Coste J, Quinquis L, D’Almeida S, Audureau E. Smoking and Health-Related Quality of Life in the General Population. Independent Relationships and Large Differences According to Patterns and Quantity of Smoking and to Gender. PLOS ONE. 2014;9(3). Available from: doi: 1371/journal.pone.0091562.

33. Bosma H, Gerritsma A, Klabbers G, Akker M. Perceived unfairness and socioeconomic inequalities in functional decline: the Dutch SMILE prospective cohort study, BMC Public Health. 2012;12(818). Available from: doi: https://doi.org/10.1186/1471-2458-12-818.

34. Delpierre C, Kelly-Irving M, Munch-Petersen M, Lauwers-Cances V, Datta G, Lepage B, Lang T. SRH and HrQOL: does social position impact differently on their link with health status? BMC Public Health. 2012;12(19). Available from: doi: 10.1186/1471-2458-12-19.

35. Otero-Rodríguez A, León-Munoz L, Banegas J, Guallar-Castillón P, Rodríguez-Artalejo F, Regidor E. Life-course socioeconomic position and change in quality of life among older adults: evidence for the role of a critical period, accumulation of exposure and social mobility. J Epidemiol Community Health. 2012;65:964-971. Available from: doi:10.1136/jech.2010.113555.

36. Dorling D, Mitchell R, Pearce J. The global impact of income inequality on health by age: An observational study. BMJ. 2007;335(873). Available from: doi: https://doi.org/10.1136/bmj.39349.507315.

37. Hemingway H, Nicholson A, Stafford M, Roberts R, Marmot M. The impact of socioeconomic status on health functioning as assessed by the SF-36 questionnaire: The Whitehall II Study. American Journal of Public Health. 1997;87(9):1484-1490. Available from: doi: 2105/ajph.87.9.1484.

38. McMichael AJ. Standardized mortality ratios and the "healthy worker effect": Scratching beneath the surface. J Occup Med. 1976;18:165-8. Available from: doi: 1097/00043764-197603000-00009.

39. Shah Healthy worker effect phenomenon. Indian J Occup Environ Med. 2009;13(2): 77-79. Available from: doi: 10.4103/0019-5278.55123.

40. WHO: Protecting workers' health. https://www.who.int/news-room/fact-sheets/detail/protecting-workers'-health (2017). Accessed 25 Feb 2019.

41. Dorynska A, Pajak A, Kubinova R, Malyutina S, Tamosiunas A, Pikhart H, et al. Socioeconomic circumstances, health behaviours and functional limitations in older persons in four Central and Eastern European populations. Age and Ageing. 2021;41:728-73. Available from: doi: 10.1093/ageing/afs114.

42. Lente E, Barry M, Molcho M, Morgan K, Watson D, Harrington J, McGee H. Measuring population mental health and social well-being. Int J Public Health. 2012;57:421-430. Available from: doi: 10.1007/s00038-011-0317-x.

43. Sumra KM, Schillaci AM. Stress and the Multiple-Role Woman: Taking a Closer Look at the "Superwoman". PLoS One. 2015;10(3). Available from: doi: 1371/journal.pone.0120952.

44. Wanderley AC, Silva G, Marques E, Oliveira J, Mota J, Carvalho J. Associations between objectively assessed physical activity levels and fitness and self-reported health-related quality of life in community-dwelling older adults. Qual Life Res. 2011;20(9):1371-1378. Available from: doi: https://doi.org/10.1007/s11136-011-9875-x.

\section{Tables}


Table 1: Interaction of education, income and classification of occupation with quality of life - Physical dimension

\begin{tabular}{|c|c|c|c|c|c|c|}
\hline \multirow{3}{*}{$\begin{array}{r}P C S \\
\text { Education Level }\end{array}$} & \multicolumn{2}{|r|}{ Overall } & \multicolumn{2}{|r|}{ Male } & \multicolumn{2}{|r|}{ Female } \\
\hline & $\mathbf{N}$ & $M(S D)$ & $\mathbf{N}$ & $M(S D)$ & $\mathbf{N}$ & $M(S D)$ \\
\hline & (Number) & Mean (standard Deviation) & (Number) & Mean (standard Deviation) & (Number) & Mean (standard Deviation) \\
\hline None/Primary & 26 & $41,95(10,86)$ & 15 & $44,35(9,49)$ & 11 & $38,68(12,18)$ \\
\hline Secondary-Lower & 56 & $43,46(9,37)$ & 26 & $43,99(9,09)$ & 30 & $42,99(9,74)$ \\
\hline Secondary-Upper & 191 & $49,78(7,02)$ & 104 & $49,68(6,83)$ & 87 & $49,89(7,28)$ \\
\hline Undergraduate & 146 & $53,05(6,11)$ & 63 & $53,09(6,21)$ & 83 & $53,03(6,07)$ \\
\hline Postagraduate & 27 & $54,89(5,35)$ & 13 & $52,63(6,40)$ & 14 & $56,99(3,10)$ \\
\hline$P$-value & & $<0,001$ & & $<0,001$ & & $<0,001$ \\
\hline Per category increase (95\% C.I.) & & 3,81 & & 3,04 & & 4,58 \\
\hline & & $(3,08-4,53)$ & & $(2,03-4.05)$ & & $(3,55-5,62)$ \\
\hline$P$ for trend & & $<0.001$ & & $<0.001$ & & $<0.001$ \\
\hline$P$ for interaction & & & & & & 0,16 \\
\hline $\operatorname{Income}(€)$ & $\mathbf{N}$ & $M(S D)$ & $\mathbf{N}$ & $M(S D)$ & $\mathbf{N}$ & $M(S D)$ \\
\hline$<1000$ & 63 & $42,61(9,94)$ & 21 & $42,11(8,89)$ & 42 & $42,86(10,52)$ \\
\hline $10001-1500$ & 117 & $48,55(7,82)$ & 59 & $47,39(7,70)$ & 58 & $49,73(7,82)$ \\
\hline $1501-2000$ & 119 & $51,16(7,33)$ & 64 & $50,78(7,79)$ & 55 & $51,61(6,79)$ \\
\hline $2001-2500$ & 77 & $53,19(5,29)$ & 40 & $53,13(5,17)$ & 37 & $53,25(5,50)$ \\
\hline $3001-5000$ & 40 & $52,25(6,22)$ & 20 & $51,83(5,64)$ & 20 & $52,68(6,87)$ \\
\hline$>5001$ & 33 & $52,80(6,61)$ & 21 & $51,92(5,80)$ & 12 & $54,33(7,86)$ \\
\hline$P$-value & & $<0,001$ & & $<0,001$ & & \\
\hline Per category increase & & 2,00 & & 1,84 & & 2,23 \\
\hline (95\% C.I.) & & $(1,50-2,50)$ & & $(1,16-2,52)$ & & $(1,49-2,97)$ \\
\hline$P$ for trend & & $<0.001$ & & $<0.001$ & & $<0.001$ \\
\hline$P$ for interaction & & & & & & 0,92 \\
\hline Classification of occupation & $\mathbf{N}$ & $M(S D)$ & $\mathbf{N}$ & $M(S D)$ & $\mathbf{N}$ & $M(S D)$ \\
\hline Level 1 & 17 & $48,31(7,70)$ & 7 & $49,86(3,96)$ & 10 & $47,22(9,58)$ \\
\hline Level 2 & 123 & $51,03(6,91)$ & 44 & $49,97(7,90)$ & 79 & $51,63(6,27)$ \\
\hline Level 3 & 99 & $51,97(5,90)$ & 81 & $51,44(5,78)$ & 18 & $54,34(5,99)$ \\
\hline Level 4 & 71 & $53,84(5,06)$ & 35 & $53,91(4,27)$ & 36 & $53,77(5,78)$ \\
\hline$P$-value & & 0,002 & & 0,04 & & 0,01 \\
\hline Per category increase & & 1,51 & & 1,68 & & 1,58 \\
\hline (95\% C.I.) & & $(0,72-2,31)$ & & $(0,50-2,86)$ & & $(0,46-2,71)$ \\
\hline$P$ for trend & & $<0,001$ & & 0,005 & & 0,006 \\
\hline$P$ for interaction & & & & & & 0,31 \\
\hline
\end{tabular}


Table 2: Interaction of education, income and classification of occupation with quality of life - Mental dimension

\begin{tabular}{|c|c|c|c|c|c|c|}
\hline \multirow{3}{*}{$\begin{array}{r}\text { MCS } \\
\text { Education Level }\end{array}$} & \multicolumn{2}{|r|}{ Overall } & \multicolumn{2}{|r|}{ Male } & \multicolumn{2}{|r|}{ Female } \\
\hline & $\mathbf{N}$ & $M(S D)$ & $\mathbf{N}$ & $M(S D)$ & $\mathbf{N}$ & $M(S D)$ \\
\hline & (Number) & Mean (standard Deviation) & (Number) & Mean (standard Deviation) & (Number) & Mean (standard Deviation) \\
\hline None/Primary & 26 & $46,18(11,04)$ & 15 & $47,95(10,77)$ & 11 & $43,77(11,45)$ \\
\hline Secondary-Lower & 56 & $49,30(8,93)$ & 26 & $49,73(7,37)$ & 30 & $48,91(10,20)$ \\
\hline Secondary-Upper & 191 & $49,59(7,35)$ & 104 & $51,22(6,71)$ & 87 & $47,63(7,64)$ \\
\hline Undergraduate & 146 & $51,25(6,50)$ & 63 & $52,70(6,00)$ & 83 & $50,15(6,68)$ \\
\hline Postagraduate & 27 & $52,61(5,89)$ & 13 & $52,45(7,51)$ & 14 & $52,75(4,17)$ \\
\hline$P$-value & & 0,005 & & 0,10 & & 0,015 \\
\hline Per category increase & & 1,40 & & 1,32 & & 1,65 \\
\hline (95\% C.I.) & & $(0,66-2,14)$ & & $(0,34-2,30)$ & & $(0,56-2,74)$ \\
\hline$P$ for trend & & $<0,001$ & & 0,008 & & 0,003 \\
\hline$P$ for interaction & & & & & & 0,56 \\
\hline Income $(€)$ & $\mathbf{N}$ & $M(S D)$ & $\mathbf{N}$ & $M(S D)$ & $\mathbf{N}$ & $M(S D)$ \\
\hline$<1000$ & 63 & $43,88(10,80)$ & 21 & $43,79(10,36)$ & 42 & $43,92(11,14)$ \\
\hline $10001-1500$ & 117 & $49,53(7,13)$ & 59 & $50,35(7,36)$ & 58 & $48,70(6,85)$ \\
\hline $1501-2000$ & 119 & $51,24(6,16)$ & 64 & $52,09(5,84)$ & 55 & $50,26(6,44)$ \\
\hline $2001-2500$ & 77 & $51,90(6,32)$ & 40 & $53,58(4,95)$ & 37 & $50,09(7,15)$ \\
\hline $3001-5000$ & 40 & $53,19(4,40)$ & 20 & $54,49(3,71)$ & 20 & $51,89(4,74)$ \\
\hline$>5001$ & 33 & $51,91(5,44)$ & 21 & $51,83(6,02)$ & 12 & $52,04(4,49)$ \\
\hline$P$-value & & $<0,001$ & & $<0,001$ & & $<0,001$ \\
\hline Per category increase (95\% C.I.) & & $1,56(1,10-2,04)$ & & $1,40(0,77-2,04)$ & & $1,57(0,86-2,29)$ \\
\hline$P$ for trend & & $<0,001$ & & $<0,001$ & & $<0,001$ \\
\hline$P$ for interaction & & & & & & 0,72 \\
\hline Classification of occupation & $\mathbf{N}$ & $M(S D)$ & $\mathbf{N}$ & $M(S D)$ & $\mathbf{N}$ & $M(S D)$ \\
\hline Level 1 & 17 & $51,31(5,52)$ & 7 & $52,98(2,44)$ & 10 & $50,15(6,83)$ \\
\hline Level 2 & 123 & $48,80(8,00)$ & 44 & $50,89(7,67)$ & 79 & $47,63(7,99)$ \\
\hline Level 3 & 99 & $52,70(4,53)$ & 81 & $53,02(4,18)$ & 18 & $51,23(5,76)$ \\
\hline Level 4 & 71 & $51,51(5,70)$ & 35 & $52,73(5,48)$ & 36 & $50,32(5,73)$ \\
\hline$P$-value & & $<0,001$ & & 0,22 & & 0,11 \\
\hline Per category increase & & 1,17 & & 0,67 & & 1,01 \\
\hline (95\% C.I.) & & $(0,34-2,01)$ & & $(-0,40,1.75)$ & & $(-0.25,2.27)$ \\
\hline$P$ for trend & & 0,006 & & 0,22 & & 0,11 \\
\hline$P$ for interaction & & & & & & 0,90 \\
\hline
\end{tabular}

Table 3: Social class (income, education, classification of occupation) and health behaviors 


\begin{tabular}{|c|c|c|c|c|c|c|c|c|c|c|c|c|c|c|c|}
\hline & \multicolumn{6}{|c|}{ Income } & \multicolumn{5}{|c|}{ Education } & \multicolumn{4}{|c|}{ Classification of occupation } \\
\hline & $<1000$ & $\begin{array}{l}1001- \\
1500\end{array}$ & $\begin{array}{l}1501- \\
2000\end{array}$ & $\begin{array}{l}2001- \\
2500\end{array}$ & $\begin{array}{l}3000- \\
5000\end{array}$ & $>5000$ & $\begin{array}{l}\text { None } \\
\text { Primary }\end{array}$ & $\begin{array}{l}\text { Secondary- } \\
\text { Lower }\end{array}$ & $\begin{array}{l}\text { Secondary- } \\
\text { Upper }\end{array}$ & Undergraduate & Postgraduate & $\begin{array}{l}\text { Level } \\
1\end{array}$ & $\begin{array}{l}\text { Level } \\
2\end{array}$ & $\begin{array}{l}\text { Level } \\
3\end{array}$ & $\begin{array}{l}\text { Level } \\
4\end{array}$ \\
\hline Smoking & & & & & & & $42.3 \%$ & $51.8 \%$ & $55 \%$ & $68.5 \%$ & $74.1 \%$ & & & & \\
\hline$<1$ pack years of smoking & $55.6 \%$ & $52.1 \%$ & $64.7 \%$ & $62.3 \%$ & $67.5 \%$ & $54.5 \%$ & $0 \%$ & $14.3 \%$ & $10.5 \%$ & $13 \%$ & $7.4 \%$ & $35.3 \%$ & $60.2 \%$ & $50.5 \%$ & $70.4 \%$ \\
\hline 1-25 pack years of smoking & $9.5 \%$ & $12 \%$ & $7.6 \%$ & $10.4 \%$ & $17.5 \%$ & $15.2 \%$ & $26.9 \%$ & $16.1 \%$ & $19.9 \%$ & $11.6 \%$ & $11.1 \%$ & $17.6 \%$ & $13 \%$ & $8.1 \%$ & $14.1 \%$ \\
\hline $\begin{array}{r}>25>50 \text { pack years of } \\
\text { smoking }\end{array}$ & $14.3 \%$ & $20.5 \%$ & $16 \%$ & $14.3 \%$ & $15 \%$ & $15.2 \%$ & $30.8 \%$ & $17.9 \%$ & $14.7 \%$ & $6.8 \%$ & $7.4 \%$ & $35.3 \%$ & $17.9 \%$ & $25.3 \%$ & $7 \%$ \\
\hline$>50$ pack years of smoking & $20.6 \%$ & $15.4 \%$ & $11.8 \%$ & $13 \%$ & $0 \%$ & $15.2 \%$ & 0.006 & & & & & $11.8 \%$ & $8.9 \%$ & $16.2 \%$ & $8.5 \%$ \\
\hline$p$-value & 0.36 & & & & & & & & & & & 0.02 & & & \\
\hline Alcohol consumption & & & & & & & $7.7 \%$ & $3.6 \%$ & $2.6 \%$ & $4.1 \%$ & $0 \%$ & & & & \\
\hline Often or daily & $1.6 \%$ & $3.4 \%$ & $4.2 \%$ & $1.3 \%$ & $5 \%$ & $6.1 \%$ & $3.8 \%$ & $14.3 \%$ & $10.5 \%$ & $8.2 \%$ & $7.4 \%$ & $0 \%$ & $4.1 \%$ & $6.1 \%$ & $1.4 \%$ \\
\hline 1-2 times a week & $7.9 \%$ & $10.3 \%$ & $12.6 \%$ & $9.1 \%$ & $5 \%$ & $6.1 \%$ & $23.1 \%$ & $12.5 \%$ & $20.9 \%$ & $30.1 \%$ & $18.5 \%$ & $11.8 \%$ & $12.2 \%$ & $8.1 \%$ & $12.7 \%$ \\
\hline 2-3 times a month & $15.9 \%$ & $21.4 \%$ & $26.1 \%$ & $31.2 \%$ & $20 \%$ & $21.2 \%$ & $30.8 \%$ & $19.6 \%$ & $46.1 \%$ & $44.5 \%$ & $55.6 \%$ & $35.3 \%$ & $24.4 \%$ & $25.3 \%$ & $25.4 \%$ \\
\hline Almost once a month & $31.7 \%$ & $33.3 \%$ & $46.2 \%$ & $44.2 \%$ & $50 \%$ & $54.5 \%$ & $34.6 \%$ & $50 \%$ & $19.9 \%$ & $13 \%$ & $18.5 \%$ & $29.4 \%$ & $45.5 \%$ & $45.5 \%$ & $47.9 \%$ \\
\hline Hardly any or no & $42.9 \%$ & $31.6 \%$ & $10.9 \%$ & $14.3 \%$ & $20 \%$ & $12.1 \%$ & $<0.001$ & & & & & $23.5 \%$ & $13.8 \%$ & $15.2 \%$ & $12.7 \%$ \\
\hline$p$-value & 0.002 & & & & & & & & & & & 0.85 & & & \\
\hline Physical activity & & & & & & & $69.2 \%$ & $61.8 \%$ & $47.4 \%$ & $39 \%$ & $40.7 \%$ & & & & \\
\hline Low intensity & $69.4 \%$ & $48.3 \%$ & $42 \%$ & $44.2 \%$ & $35 \%$ & $51.5 \%$ & $23.1 \%$ & $23.6 \%$ & $31.6 \%$ & $48.6 \%$ & $48.1 \%$ & $47.1 \%$ & $41.5 \%$ & $47.5 \%$ & $38 \%$ \\
\hline Moderate intensity & $22.6 \%$ & $34.5 \%$ & $39.5 \%$ & $39 \%$ & $47.5 \%$ & $36.4 \%$ & $7.7 \%$ & $14.5 \%$ & $21.1 \%$ & $12.3 \%$ & $11.1 \%$ & $29.4 \%$ & $37.4 \%$ & $31.3 \%$ & $47.9 \%$ \\
\hline Vigorous intensity & $8.1 \%$ & $17.2 \%$ & $18.5 \%$ & $16.9 \%$ & $17.5 \%$ & $12.1 \%$ & 0.001 & & & & & $23.5 \%$ & $21.1 \%$ & $21.2 \%$ & $14.1 \%$ \\
\hline$p$-value & 0.07 & & & & & & & & & & & 0.43 & & & \\
\hline
\end{tabular}

\section{Figures}

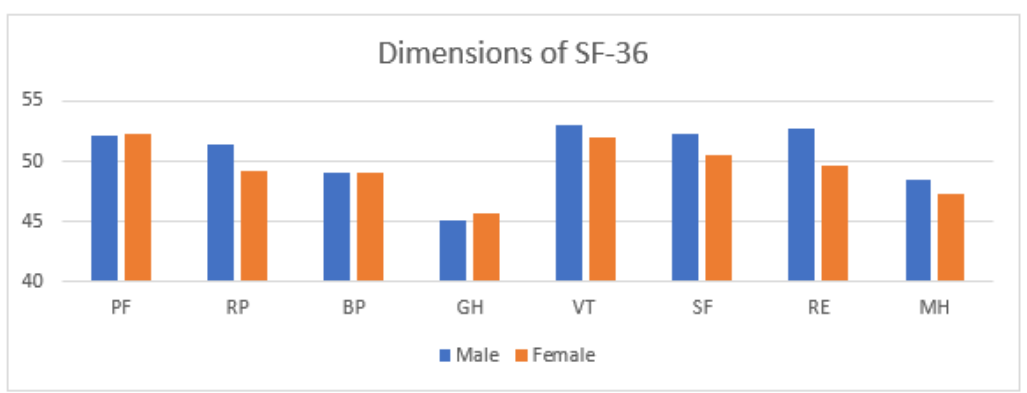

Figure 1

SF-36 dimensions in relation to gender

Quality of life in relation with education index-physical dimension

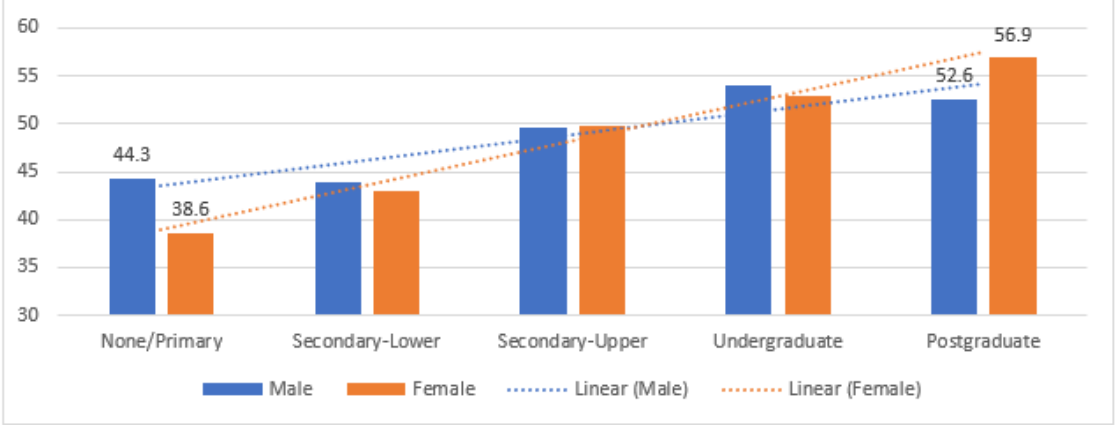

\section{Figure 2}

Quality of life in relation with education index-physical dimension 


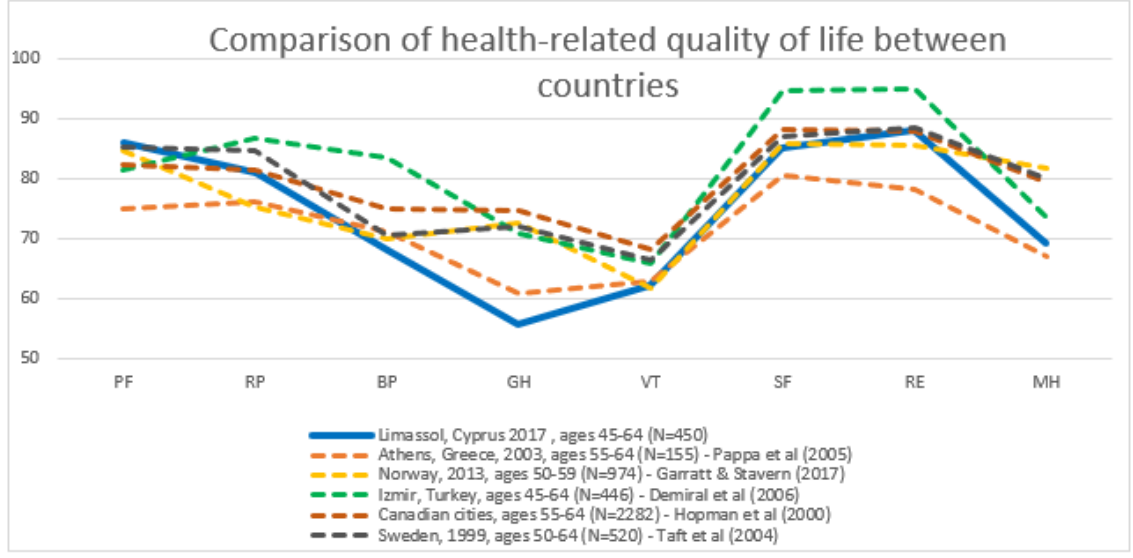

Figure 3

Comparison of health-related quality of life between countries

\section{Supplementary Files}

This is a list of supplementary files associated with this preprint. Click to download.

- Additionalfile1.docx 